See discussions, stats, and author profiles for this publication at: https://www.researchgate.net/publication/221826728

\title{
Galleria mellonella as a Model for Fungal Pathogenicity Testing
}

Article in Methods in molecular biology (Clifton, N.J.) · January 2012

DOI: 10.1007/978-1-61779-539-8_33 · Source: PubMed

\section{CITATIONS}

45

3 authors, including:

$$
\text { John P Fallon }
$$

Airmid healthgroup

7 PUBLICATIONS 207 CITATIONS

SEE PROFILE
READS

603

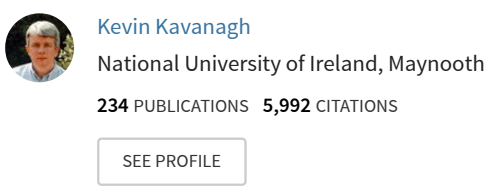

Some of the authors of this publication are also working on these related projects:

Responses of fungal pathogens to the Innate immune response View project

Phenanthroline based Transition Metal Complexes with Antibacterial Activity View project 


\title{
Author's Proof
}

\section{Chapter 33}

\section{Galleria mellonella as a Model for Fungal Pathogenicity Testing}

\author{
John Fallon, Judy Kelly, and Kevin Kavanagh
}

\begin{abstract}
Insects are convenient models for assessing the virulence of microbial pathogens or for assessing the efficacy of antimicrobial drugs and give results comparable to those that can be obtained using mammals. Galleria mellonella larvae are easy to purchase and inoculate and provide results within $48 \mathrm{~h}$. Various parameters may be used to monitor the effect of a pathogen on the insect and, as a consequence, measure its relative virulence. Larval death, changes in immune cells (haemocytes) numbers, or the extent of proliferation of the pathogen within the insect haemocoel are good indicators of virulence and of the insect's immune response. Analysing the humoral immune response also gives insight into the interaction of the pathogen with the insect. Changes in gene expression or the expression of key antimicrobial peptides provide data on this element of the insect's response and, through extrapolation, how the mammalian immune system might respond. G. mellonella larvae, therefore, provide a quick and convenient means of measuring microbial virulence and are a useful alternative to the use of mammals for this type of screening.
\end{abstract}

Key words: Aspergillus, Candida, Fungi, Galleria, Haemocytes, Microbial virulence, Mini-host 6 7 8 9

The insect immune system shares a number of structural and functional similarities with the mammalian innate immune system and, 20 as a consequence, insects may be used in place of mammals for 21 screening microbial pathogens or for assessing the potency of anti- 22 microbial drugs (1). Larvae of the greater wax moth Galleria mel- 23 lonella are inexpensive to purchase, easy to inoculate, and can give 24 results within $48 \mathrm{~h}$. We have employed G. mellonella larvae to assess 25 the virulence of yeast (2) and Aspergillus fumigatus (3), with strong 26 correlations between the virulence in larvae and mice of Candida 27 albicans (4) and Cryptococcus (5) demonstrated. The use of insects 28 as a screening model is now well established for many pathogens 


\section{Author's Proof}

J. Fallon et al.

(4-6), with Galleria and other insects, such as Drosophila and Manduca, often referred to as "mini-hosts" $(7,8)$.

Changes in G. mellonella larva viability can be used to measure the relative virulence of microbial pathogens and/or mutants. Monitoring the insect immune response to microbial pathogens can also be useful as this gives an insight into the virulence of "weak" pathogens and provides information on how the mammalian innate immune system may respond. Measuring changes in the haemocyte density and the fungal load gives information on the cellular immune response to the pathogen and the proliferation of the pathogen in the host, respectively (9). In addition, it is also possible to monitor the expression of genes for selected antimicrobial peptides as a means of assessing the humoral immune response of larvae (10). Analysing changes in the proteome of infected larvae can also be very useful for monitoring alterations in expression of low molecular weight antimicrobial peptides. We have used this latter technique to demonstrate that larvae mount a "proportionate" immune response when inoculated with pathogen-derived material (11).

Insects are also a useful in vivo screening system for assessing the potency of antimicrobial agents (12-15). In this application, larvae can be infected with the cells or conidia of a pathogen and then given a pre-determined dose of the antimicrobial agent. An alternative is possible where the larvae are given the agent in advance of the pathogen. It should be emphasised, however, that administration of an antimicrobial agent to larvae induces a protective immune response and that any protective effect could be due to the combined effect of the antimicrobial agent and the insect's enhanced immune response (15). Controls to account for the increased immune response of the insect must be included in order to see the actual effect of the drug in vivo.

The use of insects as in vivo models to assess fungal virulence has grown in popularity in recent years $(1,7,8)$. Although there are many advantages to the use of insects, G. mellonella larvae in particular, it must be emphasised that the insect immune system is only analogous to the mammalian innate immune system, and therefore, insect models give no insight into the role of the adaptive immune system in combating infections in mammals. In addition, larvae lack many of the organs attacked specifically by fungal pathogens, e.g. brain, lungs, kidneys, and spleen, so they cannot be used to model organ-specific pathologies. However, G. mellonella does provide a convenient initial screening system for studying pathogens that cause systemic infection, although as with all minihosts, validation of results may require further confirmatory mammalian testing.

This chapter describes a range of methods for use with G. mellonella larvae for evaluating the virulence of fungal pathogens or 


\section{Author's Proof}

for assessing the efficacy of antimicrobial agents. It details techniques 77 for measuring the effect of the pathogen or drug on the insect 78 immune response and describes methods for quantifying the 79 response of the larvae to the different agents.

2.1. Inoculation of Galleria mellonella Larvae with Candida albicans

\subsection{Determination of Haemocyte Density of Galleria mellonella}

2.3. Determination of Candida albicans Fungal Load in Infected Galleria mellonella Larvae

\subsection{Assessment of Caspofungin In Vivo Activity Against Candida albicans}

1. Sixth instar Galleria mellonella larvae (Lepidoptera: pyralidae, 82 greater wax moth) (Mealworm Company) (see Note 1). 83

2. Myjector syringe (Terumo Europe). 84

3. YEPD $(2 \%(\mathrm{w} / \mathrm{v})$ glucose (Sigma-Aldrich), 2\% (w/v) bacto 85 peptone (Difco), 1\%(w/v) yeast extract (Oxoid)). 86

4. Stationary phase culture of Candida albicans $\left(1-2 \times 10^{9}\right.$ cells / 87 $\mathrm{mL}$ ) grown in YEPD at $30^{\circ} \mathrm{C}$ and $200 \mathrm{rpm}$. 88

5. Phosphate buffered saline (PBS). 89

6. Petri dishes $(9 \mathrm{~cm})$. 90

7. Filter paper circles $(9 \mathrm{~cm})$. 91

1. Infected and control G. mellonella larvae. $\quad 92$

2. Sterile needles ( $23 \mathrm{G}$, Terumo). 93

3. Sterile tubes $(1.5 \mathrm{~mL})$. 94

4. 1-Phenyl-3-(2-thiazolyl)-2-thiourea. 95

5. Ice-cold PBS containing $0.37 \%(\mathrm{v} / \mathrm{v})$ 2-mercaptoethanol. 96

6. Haemocytometer. $\quad 97$

7. Microscope. 98

1. Sixth instar G. mellonella larvae. 99

2. Stationary phase culture of C. albicans. 100

3. Sterile (pre-autoclaved) pestle and mortar. 101

4. PBS. 102

5. YEPD-erythromycin agar plates: 2\%(w/v) glucose, 2\% (w/v) 103 bacteriological peptone, $1 \%(\mathrm{w} / \mathrm{v})$ yeast extract, and 2\% (w/v) 104 agar and $1 \mathrm{mg} / \mathrm{mL}$ erythromycin (Sigma-Aldrich). 105

1. C. albicans-infected G. mellonella larvae. 106

2. Caspofungin (Cancidas ${ }^{\mathrm{TM}}$, Merck \& Co.). 107

$\begin{array}{ll}3 . & 108\end{array}$

4. Petri dishes $(9 \mathrm{~cm})$. 109

5. Filter paper circles $(9 \mathrm{~cm})$. 110 


\section{Author's Proof}

J. Fallon et al.

\subsection{Extraction of} Galleria mellonella RNA and Antimicrobial Gene Expression Analysis

\subsection{Analysis of Proteomic Changes in Infected Larvae by 2D Gel Electrophoresis and LC/MS}

1. Sixth instar G. mellonella larvae.

2. Sterile (RNase-free) pestles and mortars.

3. Liquid nitrogen.

4. Sterile tubes $(1.5 \mathrm{~mL})$.

5. TRI ${ }^{\circledR}$ Reagent (Sigma-Aldrich).

6 . Vortex mixer.

7. Chloroform.

8. Isopropanol.

9. $75 \%(\mathrm{v} / \mathrm{v})$ ethanol.

10. DEPC-treated water.

11. Deoxyribonuclease I (AMP-Dl) kit (Sigma-Aldrich).

12. RNase-free agarose.

13. 10× FA buffer (200 mM 3-(N-morpholino)propanesulfonic acid (MOPS), $50 \mathrm{mM}$ sodium acetate, $10 \mathrm{mM}$ EDTA, $\mathrm{pH} 7$ ).

14. $37 \%(\mathrm{v} / \mathrm{v})$ formaldehyde.

15. $0.5 \%(\mathrm{w} / \mathrm{v})$ SDS.

16. $10 \mathrm{mg} / \mathrm{mL}$ ethidium bromide.

17. Agarose gel electrophoresis equipment.

18. $5 \times$ RNA gel loading dye (for $10 \mathrm{~mL}: 80 \mu \mathrm{L} 0.5 \mathrm{M} \mathrm{EDTA}, \mathrm{pH}$ $8,720 \mu \mathrm{L} \mathrm{37 \%} \mathrm{(v/v)} \mathrm{formaldehyde,} 2 \mathrm{~mL}$ glycerol, $3.084 \mathrm{~mL}$ formamide, $4 \mathrm{~mL} 10 \times \mathrm{FA}$ buffer, and $16 \mu \mathrm{L}$ saturated aqueous bromophenol blue solution).

19. $1 \times$ TAE buffer ( $1 / 50$ dilution of $50 \times$ stock: $24.2 \%(\mathrm{w} / \mathrm{v})$ Trisbase, $5.71 \%(\mathrm{v} / \mathrm{v})$ acetic acid, $0.05 \mathrm{M}$ EDTA $(\mathrm{pH} 8))$.

20. Nanodrop 1000 spectrophotometer.

21. Superscript III First-Strand Synthesis System (Invitrogen).

22. DMSO (molecular grade).

23. $10 \mathrm{mM}$ dNTP mix (Promega).

24. Water (molecular grade).

25. Accutaq $^{\text {TM }}$ LA DNA polymerase.

26. $10 \mu \mathrm{M}$ forward and reverse primers (Table $1,(10)$ ).

27. Thermal cycler.

28. Blue/orange $6 \times$ loading dye (Promega).

1. Pre-chilled $\left(-20^{\circ} \mathrm{C}\right) 1.5-\mathrm{mL}$ tubes.

2. Sterile deionised water.

3. Bradford reagent.

4. IEF Buffer ( $8 \mathrm{M}$ urea, $2 \mathrm{M}$ thiourea, $4 \%(\mathrm{v} / \mathrm{v})$ CHAPS, $1 \%$ Triton-X 100, $65 \mathrm{mM}$ DTT, $10 \mathrm{mM}$ tris base). 


\section{Author's Proof}

Table 1

PCR primers and conditions for analysis of antimicrobial gene expression

$\mathrm{t} 1.1$

$\mathrm{t} 1.2[\mathrm{AU} 1]$

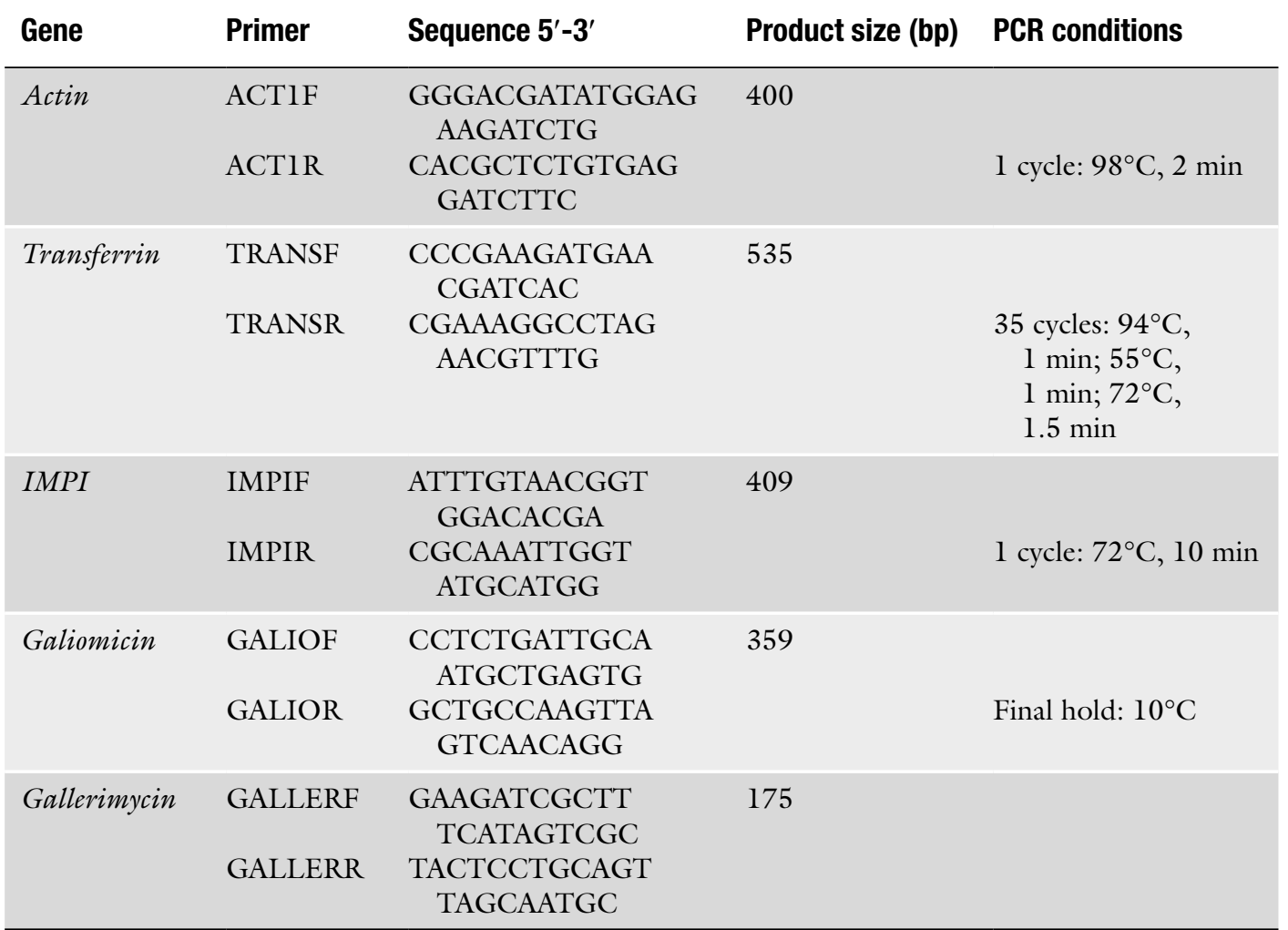

Primer sequences are taken from Bergin et al. (2007) (10) $\mathrm{t} 1.3$

$\mathrm{t} 1.4$

$\mathrm{t} 1.5$

$\mathrm{t} 1.6$

$\mathrm{t} 1.7$

$\mathrm{t} 1.8$

$\mathrm{t} 1.9$

t1. 10

t1.11

$\mathrm{t} 1.12$

$\mathrm{t} 1.13$

$\mathrm{t} 1.14$

t1.15

$\mathrm{t} 1.16$

$\mathrm{t} 1.17$

$\mathrm{t} 1.18$

t1.19

t1.20

t1.21

$\mathrm{t} 1.22$

t1.23

$\mathrm{t} 1.24$

t1.25

t1.26[AU2]

5. IPG Buffer (ampholytes) pH 3-10 (GE Healthcare). 149

6. Bromophenol blue powder. 150

7. Iso-electric focusing (IEF) machine (Ettan IPGphor II, 151 Amersham Biosciences).

8. IEF coffins (Amersham Biosciences).

9. IEF strips (GE Healthcare).

10. PlusOne strip cover fluid (GE Healthcare). 155

11. Test tubes (at least $13 \mathrm{~cm}$ long). 156

12. Dithiothreitol (DTT). 157

13. Iodoacetamide (IAA). 158

14. Equilibration buffer (30\% glycerol, 2\% SDS, $6 \mathrm{M}$ urea, $50 \mathrm{mM} 159$ tris base).

15. 1.5 M Tris-HCl, $\mathrm{pH} 8.8$.

16. $10 \%$ SDS, filter-sterilised and stored at room temperature to prevent crystallisation. 


\section{Author's Proof}

J. Fallon et al.

\subsection{Extraction and Analysis of Peptides from Galleria mellonella Larvae}

\section{Methods}

\subsection{Inoculation of Galleria mellonella Larvae with Candida albicans}

1. Place ten healthy larvae on Whatman filter paper placed in sterile 9-cm Petri dishes.

2. Grow a C. albicans culture to stationary phase $\left(1-2 \times 10^{9} / \mathrm{mL}\right)$ in YEPD broth at $30^{\circ} \mathrm{C}$, with shaking at $200 \mathrm{rpm}$. Harvest cells by centrifugation $(2,056 \times g$ for $5 \mathrm{~min})$, wash in PBS and

3. $0.1 \%(\mathrm{v} / \mathrm{v})$ trifluoroacetic acid (TFA) made in HPLC-grade water.

4. n-Hexane.

5. Ethyl acetate.

6. Bradford reagent (Biorad).

7. 1.5-mL tubes.

17. $30 \%$ acrylamide.

18. $10 \%$ ammonium persulphate.

19. $N, N, N, N^{\prime}$-Tetramethyl-ethylene diamine (TEMED).

20. SDS-PAGE standards (Bio-Rad). base, $144 \mathrm{~g}$ glycine, $10 \mathrm{~g}$ SDS in $1 \mathrm{~L}$ distilled water).

2. Agarose

Coomassie stain. acetonitrile. pels should be used to excise larger spots or bands, with sterile pipette tips useful for excising smaller gel pieces).

26. Destaining buffer (100 $\mathrm{mM}$ ammonium bicarbonate $\left(\mathrm{NH}_{4} \mathrm{HCO}_{3}\right)$ : acetonitrile; $\left.1: 1\right)$.

27. $100 \%$ acetonitrile.

28. Trypsin digestion buffer ( $13 \mathrm{ng} / \mu \mathrm{L}$ sequencing grade trypsin (Promega) in $10 \mathrm{mM} \mathrm{NH}_{4} \mathrm{HCO}_{3}, 10 \%(\mathrm{v} / \mathrm{v})$ acetonitrile).

29. Extraction buffer (1:2 (v/v) $5 \%$ formic acid: $100 \%$ acetonitrile).

30. $0.1 \%$ formic acid made using LC/MS-grade water.

31. $0.22-\mu \mathrm{m}$ cellulose filter tubes.

32. Liquid chromatography-mass spectrometry (LC-MS).

1. Peptide extraction buffer (HPLC grade methanol:glacial acetic acid: HPLC grade water, 9:0.1:0.9); chilled on ice prior to use.

2. Freeze drier for lyophilisation.$$
\text { cells by centrifugation }(2,056 \times g \text { for } 5 \mathrm{~min}) \text {, wash in PBS and }
$$ 


\section{Author's Proof}

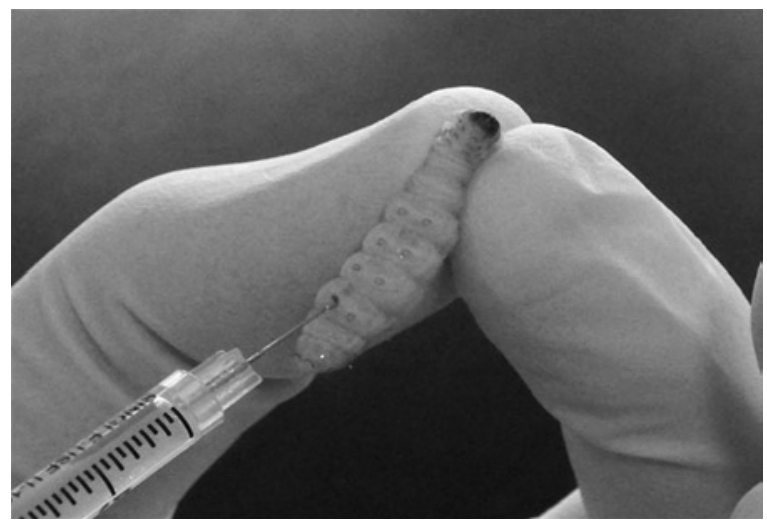

Fig. 1. Inoculation of Galleria mellonella larvae by injection through the proleg.

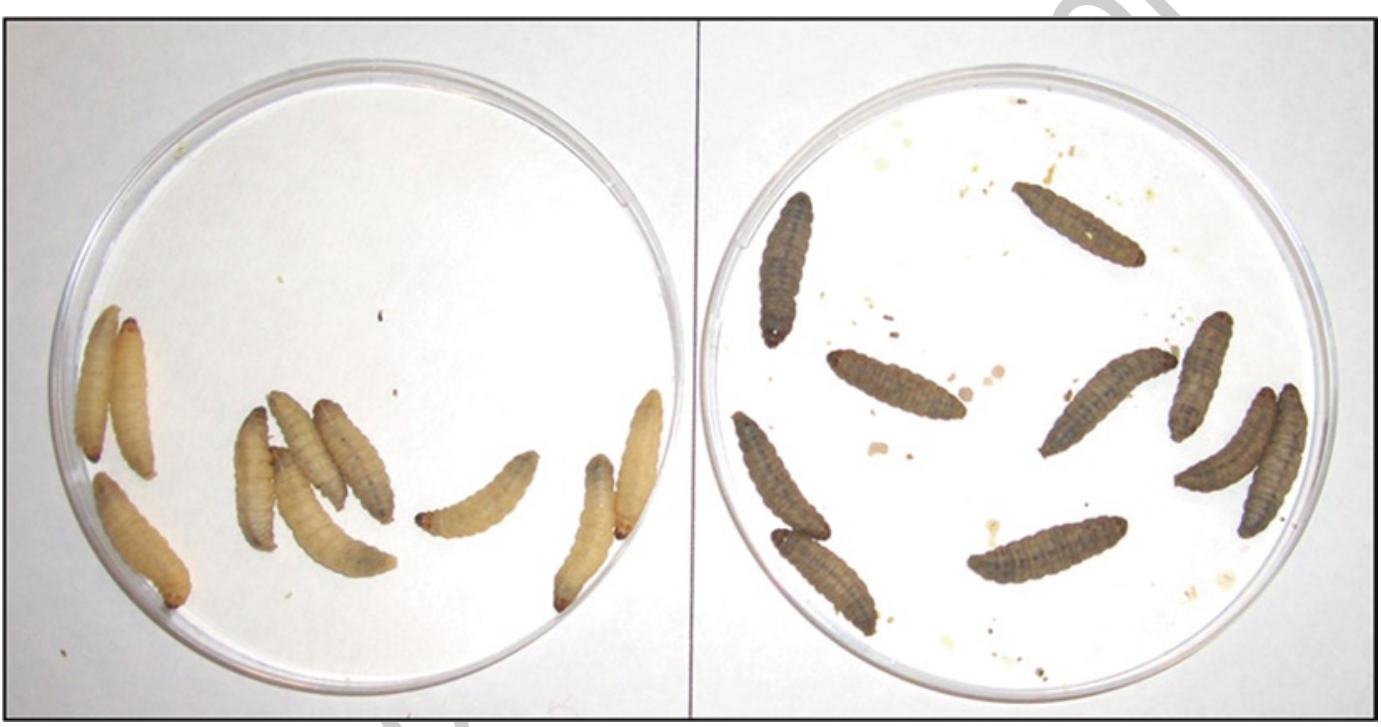

Fig. 2. Larval morphology. (a) Healthy Galleria mellonella larvae. (b) Larvae killed as a result of Aspergillus fumigatus infection $48 \mathrm{~h}$ previously. Note the dark colour of cadavers due to melanisation.

re-suspend in PBS at various cell densities, ranging from $5 \times 10^{5}, 201$ $1 \times 10^{6}, 2.5 \times 10^{6}$ to $5 \times 10^{6}$ per $20 \mu \mathrm{L}$ (see Note 2 ).

3 . Inoculate larvae by injecting $20 \mu \mathrm{L}$ through the last left proleg 203 into the haemocoel using a Myjector syringe (Fig. 1) and place 204 at $30^{\circ} \mathrm{C}$ in the dark for up to $96 \mathrm{~h}$ (see Note 3). Untouched 205 larvae and larvae injected with $20 \mu \mathrm{L}$ of water or PBS should 206 be included as controls.

4. Assess larvae at regular intervals (every $2 \mathrm{~h}$ ) for viability and 208 disease progression. For assessment of viability, larvae should 209 be gently probed with a needle, and if no response is observed, 210 the larvae may be considered to be dead. Changes in cuticle 211 melanisation can also be used to monitor the severity of an 212 infection (Fig. 2) (see Note 4). 


\section{Author's Proof}

J. Fallon et al.

3.2. Determination of Haemocyte Density of Galleria mellonella

\subsection{Determination} of Fungal Load of Galleria mellonella Inoculated with Candida albicans

\subsection{Assessment} of In Vivo Activity of Caspofungin in C. albicans-Infected G. mellonella

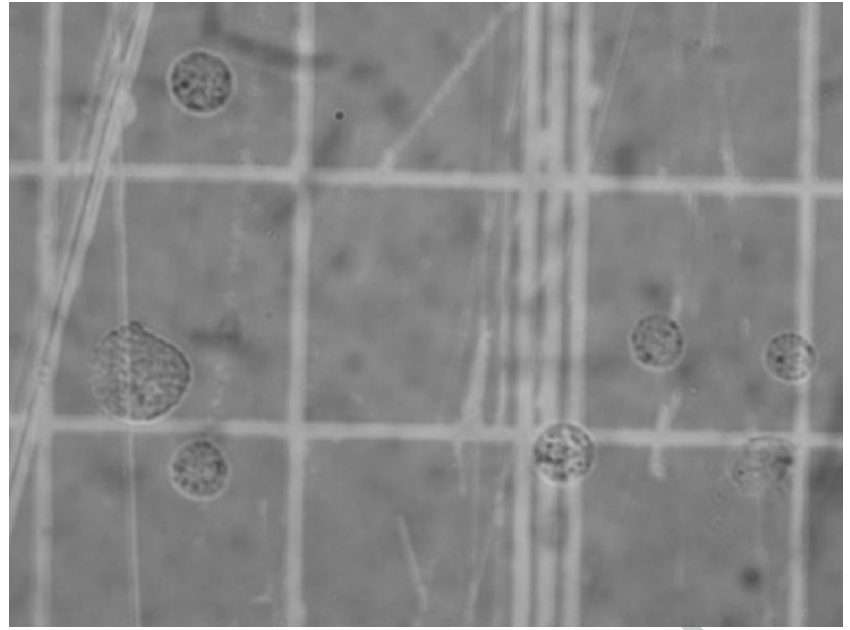

Fig. 3. G. mellonella haemocytes. G. mellonella haemocytes were extracted and viewed by light microscopy (40× objective). Note variations in size and granularity.

1. Pierce the backs of the anterior end ("head") of three randomly chosen larvae with a sterile needle and collect the yellow haemolymph ("blood") into a single pre-chilled tube containing a few grains of 1-phenyl-3-(2-thiazolyl)-2-thiourea (see Notes 5 and 6 ).

2. Dilute haemolymph 1 in 10 in cold PBS containing $0.37 \%$ (v/v) 2-mercaptoethanol to reduce clotting and melanisation. Mix gently by pipetting.

3. Count haemocytes on a haemocytometer (Fig. 3) and calculate the original density in the larvae (see Note 7 ).

1. Inoculate ten $G$. mellonella larvae with $C$. albicans $\left(5 \times 10^{5}\right.$ cells $\left./ 20 \mu \mathrm{L}\right)$ and incubate for $24 \mathrm{~h}$ at $30^{\circ} \mathrm{C}$.

2. Select three random larvae and place in a sterile pestle with $3 \mathrm{~mL} \mathrm{PBS}$ and grind to a pulp with a mortar.

3. Dilute the resulting homogenate with PBS and plate $100-\mu \mathrm{L}$ samples onto YEPD-erythromycin plates (see Notes 8 and 9).

4. Incubate plates at $30^{\circ} \mathrm{C}$ for $24 \mathrm{~h}$ and enumerate colony-forming units.

5. Calculate larval fungal load by multiplying the colony-forming units by the relevant dilution factor (see Note 10).

1. Infect G. mellonella larvae with $C$. albicans as described above (see Note 11), including relevant control groups (see Note 12).

2. At $1 \mathrm{~h}$ post-infection, inoculate larvae with a $20-\mu \mathrm{L}$ volume of caspofungin (e.g. $0.2,0.1$, or $0.05 \mu \mathrm{g} / \mathrm{mL}$ ) or PBS (as control). Place at $30^{\circ} \mathrm{C}$ for up to $96 \mathrm{~h}$. 


\subsection{Extraction of Galleria mellonella RNA and Antimicrobial Gene Expression Analysis}

3. Assess larval viability at 24-h intervals. 239

4. As an alternative to assess the effectiveness of caspofungin, 240 inject larvae with caspofungin 1 or $4 \mathrm{~h}$ prior to infection with 241 C. albicans.

For RNA extractions, RNase-free materials should be used and pre- 243 cautions taken to minimise RNase contamination (see Note 13). 244

1. Place three G. mellonella larvae in a mortar (see Note 14); 245 cover with liquid nitrogen (about $5 \mathrm{~mL}$ ). Grind with a pestle 246 until the larvae resemble a fine powder. 247

2. Add $3 \mathrm{~mL} \mathrm{TRI}{ }^{\circledR}$ reagent and mix. Leave to rise slightly in tem- 248 perature until liquid becomes less viscous. 249

3. Transfer liquid to $1.5-\mathrm{mL}$ tubes $(1 \mathrm{~mL}$ in each) and centrifuge 250 at $12,000 \times g$ for $10 \mathrm{~min}$ at $4^{\circ} \mathrm{C}$.

4. Transfer the supernatant to a new tube. Do not pool superna- 252 tants. To each tube, add $200 \mu \mathrm{L}$ chloroform and vortex for 253 $15 \mathrm{~s}$. Leave to stand at room temperature for $10 \mathrm{~min}$. 254

5. Centrifuge tubes as before and transfer the upper layer to a 255 new tube and add $500 \mu \mathrm{L}$ isopropanol. Invert the tubes several 256 times and allow to stand at room temperature for $10 \mathrm{~min} . \quad 257$

6. Centrifuge tubes as before. Discard the supernatant and wash 258 the pellet in $100 \mu \mathrm{L} 75 \%$ ethanol by vortexing. Centrifuge 259 tubes as before and remove ethanol completely. Allow tubes to 260 air dry by placing in a Laminar flow hood on ice. 261

7. Re-suspend the pellet in $80 \mu \mathrm{L}$ DEPC-treated water. 262

8. Remove contaminating DNA using the deoxyribonuclease I 263 (AMP-Dl) kit in accordance with the manufacturer's instruc- 264 tions to DNase treat samples. 265

9. Determine RNA concentration using the Nanodrop 1000266 $\begin{array}{ll}\text { spectrophotometer. } & 267\end{array}$

10. Aliquot RNA and store at $-80^{\circ} \mathrm{C}$. 268

11. Prior to use, wash the gel rig and tank with $0.5 \%(\mathrm{w} / \mathrm{v})$ SDS, 269 rinse with DEPC-treated water followed by ethanol, and allow 270 $\begin{array}{ll}\text { to air dry. } & 271\end{array}$

12. In order to visualise RNA, prepare $100 \mathrm{~mL}$ of $1 \%(\mathrm{w} / \mathrm{v})$ aga- 272 rose in $1 \times$ FA buffer. Heat the mixture until dissolved and 273 allow to cool to hand-hot. Add $1.8 \mathrm{~mL} \mathrm{37 \%} \mathrm{(v/v)} \mathrm{formalde-} 274$ hyde plus $1 \mu \mathrm{L}$ of $10 \mathrm{mg} / \mathrm{ml}$ ethidium bromide prior to pour- 275 ing the gel. 276

13. Prior to running, equilibrate the gel in $1 \times$ FA running buffer 277 for at least $30 \mathrm{~min}$.

14. Add $4 \mu \mathrm{L}$ RNA to $4 \mu \mathrm{L} 5 \times$ RNA gel loading dye; heat to $65^{\circ} \mathrm{C} 279$ for $5 \mathrm{~min}$ and chill on ice. 


\section{Author's Proof}

J. Fallon et al.

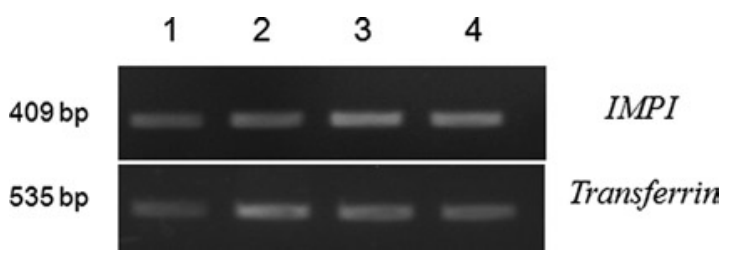

Fig. 4. Visualisation of antimicrobial gene expression. RNA extracted from infected larvae was used as the template for CDNA synthesis and subsequent PCR reactions to examine expression of antimicrobial peptide genes; (1) larvae injected with PBS, (2) larvae injected with $0.19 \mu \mathrm{g} / \mathrm{mL}$ caspofungin, (3) larvae injected with $0.095 \mu \mathrm{g} / \mathrm{mL}$ caspofungin, and (4) larvae injected with $0.048 \mu \mathrm{g} / \mathrm{mL}$ caspofungin.

15. Load the samples into the wells of the gel and run at $50 \mathrm{~V}$ in $1 \times$ FA buffer for approximately $40 \mathrm{~min}$. Visualise bands using a UV transilluminator.

16. Synthesise cDNA using $1 \mu \mathrm{g}$ RNA and the Superscript III First-Strand Synthesis System for RT-PCR kit according to manufacturer's instructions. cDNA should be stored at $-20^{\circ} \mathrm{C}$.

17. Analyse expression of G. mellonella antimicrobial genes by qRT-PCR using primers and PCR cycle conditions outlined in Table 1. The Actin housekeeping gene can be used as a control. Each PCR reaction $(20 \mu \mathrm{L}$ volume $)$ contains $1 \mu \mathrm{g} / \mu \mathrm{L}$ cDNA, $2 \mu \mathrm{L} 10 \times$ LA Buffer, $0.4 \mu \mathrm{L}$ DMSO, $1 \mu \mathrm{L} 10 \mathrm{mM}$ dNTP mix, 14.6 $\mu \mathrm{L}$ water, $0.4 \mu \mathrm{L} 10 \mu \mathrm{M}$ forward primer, $0.4 \mu \mathrm{L} 10 \mu \mathrm{M}$ reverse primer, and $0.2 \mu \mathrm{L} \mathrm{AccuTaq}^{\mathrm{TM}}$ LA DNA polymerase. Solutions were mixed by pipetting and placed immediately into the thermal cycler.

18. Mix $4 \mu \mathrm{L}$ of PCR product with $4 \mu \mathrm{L}$ blue/orange $6 \times$ loading dye.

19. Visualise PCR products by running samples on a $1 \%(\mathrm{w} / \mathrm{v})$ agarose gel ( $1 \mathrm{~g}$ agarose in $100 \mathrm{~mL} 1 \times \mathrm{TAE})$ with the addition of $2 \mu \mathrm{L} 10 \mathrm{mg} / \mathrm{mL}$ ethidium bromide. Run gel at $50 \mathrm{~V}$ for $30 \mathrm{~min}$ and view using a UV transilluminator (Fig. 4).

3.6. Analysis of

Proteomic Changes in Infected Larvae by $2 D$ Gel Electrophoresis and LC/MS
The gel fragment tryptic digestion part of the protocol is a modification of the method described by Schevchenko et al. (17).

1. Bleed ten fungal-infected G. mellonella larvae into a pre-chilled 1.5-mL tube (as in subheading 3.2) and centrifuge at $800 \times g$ for $2 \mathrm{~min}$ at $4^{\circ} \mathrm{C}$ to pellet haemocytes. Transfer the cell-free supernatant to a fresh tube.

2. Make a $\mathbf{1}$ in $\mathbf{5 0}$ dilution of the crude cell-free haemolymph in deionised water and quantify protein content using Bradford method as per the manufacturer's instructions. Calculate the protein concentration of the neat cell-free haemolymph. 
3. Add $350 \mu \mathrm{g}$ protein to $100 \mu \mathrm{L}$ IEF buffer and allow to solubi- 313 lise for approximately $15 \mathrm{~min}$ at room temperature. 314

4. Add $2 \mu \mathrm{L}$ ampholytes, pipette four to five times to mix, and 315 allow to stand at room temperature for $15 \mathrm{~min}$. 316

5. Add a further $150 \mu \mathrm{L}$ IEF buffer and add a few grains of bro- 317 mophenol blue to the solution and mix by pipetting. 318

6. Pipette $250 \mu \mathrm{L}$ of the sample into an IEF coffin, tilt the IEF cof- 319 fin to ensure an even distribution, and place a 13-cm IEF strip 320 on top. Cover the strip with PlusOne DryStrip Cover Fluid. 321

7. Place the coffins into the IEF machine. Apply the following 322 strip-focusing method per strip: $12 \mathrm{~h}$ at $50 \mathrm{~V}, 15 \mathrm{~min}$ at $250 \mathrm{~V}, 323$ increasing to $8,000 \mathrm{~V}$ with gradient increase over $5 \mathrm{~h}$, and then 324 hold at $8 \mathrm{~h}$ at $8,000 \mathrm{~V}$. Once focusing is complete, strips may be 325 stored at $-70^{\circ} \mathrm{C}$ with the gel side of IEF strip facing upwards. $\quad 326$

8. Aliquot $10 \mathrm{~mL}$ equilibration buffer into two separate test tubes. 327 Dissolve $0.2 \mathrm{~g}$ DTT in the first equilibration tube and $0.4 \mathrm{~g} \quad 328$ iodoacetamide in the second equilibration tube. Add a few 329 grains of bromophenol blue to the second equilibration tube. 330

9. Transfer the IEF strip to the first equilibration solution, seal 331 with paraffin film, and incubate horizontally on a rocking table 332 for $15 \mathrm{~min}$.

10. Transfer to the second equilibration solution and allow to 334 equilibrate as in step 9. 335

11. Once equilibration is complete, rinse briefly with deionised 336 water and place on top of the separating gel (see Note 15). 337 Prepare a gel for 2D electrophoresis (see Note 16). 338

12. Place a piece of filter paper soaked in SDS-PAGE ladder at the 339 corner of the gel and seal with a 1\% agarose solution made with 340 $1 \times$ SDS-PAGE running buffer. 341

13. Run gel at $80 \mathrm{~V}$ overnight and stain with Coomassie stain 342 (Fig. 5).

14. Cut gel pieces from 2D gels (see Note 17) and transfer to indi- 344 vidual siliconised tubes.

15. Wash stain from the gel piece using destaining buffer $(200 \mu \mathrm{L}) \quad 346$ at room temperature and vortex occasionally. Repeat this step 347 if required to remove all of the stain (see Note 18).

16. Remove all of the destaining buffer and resuspend the gel 349 pieces in sufficient $100 \%$ acetonitrile to cover the gel piece (see 350 Note 19).

17. Remove the acetonitrile. At this point, gel pieces can be stored at $-20^{\circ} \mathrm{C}$; alternatively proceed to step 20 .

18. Add $60 \mu \mathrm{L}$ trypsin digestion buffer to each tube containing gel 354 pieces. 


\section{Author's Proof}

J. Fallon et al.

3
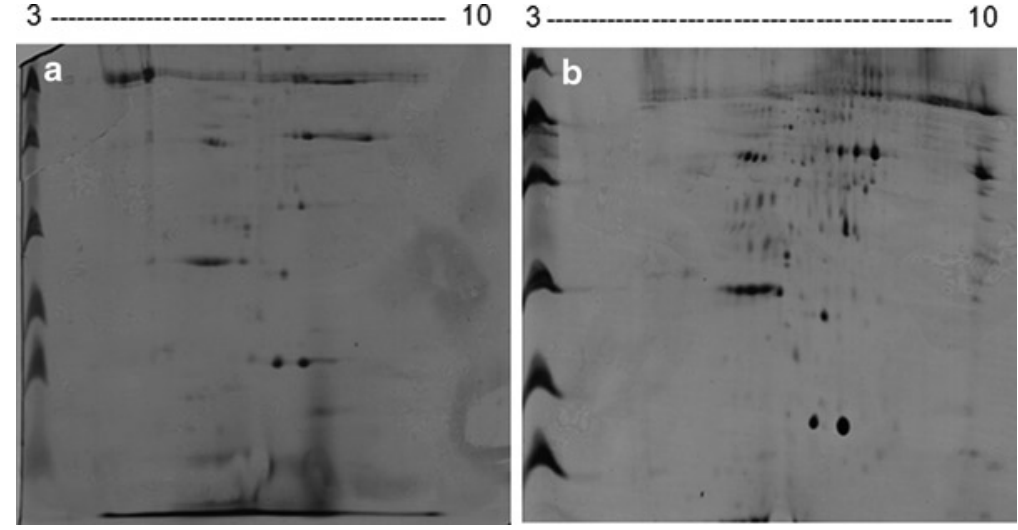

Fig. 5. G. mellonella larval haemolymph proteome. A control larvae and proteome of larvae challenged with beta-glucan. Note the increased expression of spots corresponding to specific proteins.

19. Place all tubes on ice for $30 \mathrm{~min}$ (see Note 20).

20. Add sufficient trypsin buffer to cover the gel pieces and keep on ice for approximately $60 \mathrm{~min}$. Inspect all tubes to ensure that all the gel pieces remain covered.

21. Add $10 \mathrm{mM}$ AmBic: $10 \% \mathrm{vol} / \mathrm{vol}$ buffer to ensure that the gel plug is hydrated during enzymatic cleavage (see Note 21 ).

22 . Incubate tubes at $37^{\circ} \mathrm{C}$ for $4-24$ h to allow for tryptic digestion of protein (see Note 22).

23. Centrifuge the tryptic digests at $5,000 \times g$ for $5 \mathrm{~min}$ and transfer the supernatant to a clean tube.

24. Add approximately $100 \mu \mathrm{L}$ extraction buffer to the remaining gel piece pellet and incubate at $37^{\circ} \mathrm{C}$ for $15 \mathrm{~min}$ to extract peptides.

25. Centrifuge and transfer the supernatant to the tryptic digestion supernatant from step 23.

26. Vacuum dry the pooled supernatants to completion.

27. Store at $-20^{\circ} \mathrm{C}$ until required for LC/MS analysis.

28. Prior to LC/MS analysis, resuspend the dried supernatants in $15 \mu \mathrm{L} 0.1 \%$ formic acid and remove any debris by adding to a $0.22-\mu \mathrm{m}$ cellulose acetate filter and centrifuging the tube at $20,000 \times g$ for $3 \mathrm{~min}$.

29. Transfer $10 \mu \mathrm{L}$ of each sample to an LC/MS vial for analysis (see Note 23).

3.7. Extraction and Analysis of Peptides from G. mellonella Larvae
Peptide extraction is performed by the method of Cytrynska et al. (16) with slight modifications.

1. Bleed ten larvae into a pre-chilled $1.5-\mathrm{mL}$ tube and centrifuge at $800 \times g$ for $2 \mathrm{~min}$ at $4^{\circ} \mathrm{C}$ to pellet haemocytes. Transfer the cell-free supernatant to a fresh tube. 
2. Make a $1 / 10$ dilution of cell free haemolymph in peptide 383 extraction buffer and leave to stand on ice for $30 \mathrm{~min}$ to pre- 384 cipitate high-molecular-weight proteins. 385

3. Centrifuge at $20,000 \times g$ for $30 \mathrm{~min}$ at $4^{\circ} \mathrm{C}$. 386

4. Transfer supernatant to a fresh tube and lyophilise in a freeze 387 drier until dry. 388

5. Resuspend lyophilised extract in $200 \mu \mathrm{L} 0.1 \%$ TFA. 389

6 . Add an equal volume of $n$-hexane and mix thoroughly to 390 remove lipid. Centrifuge at $20,000 \times g$ for $10 \mathrm{~min}$. 391

7. Remove the upper lipid-containing fraction and add an equal 392 volume of ethyl acetate to the lower water fraction. Centrifuge 393 at $20,000 \times g$ for $10 \mathrm{~min}$. 394

8. Remove the lower aqueous layer to a clean $1.5-\mathrm{mL}$ tube. 395

9. Quantify the protein content by Bradford assay as per the man- 396 ufacturer's instructions. 397

10. Equalise the protein concentration in a $100 \mu \mathrm{L}$ volume to 398 allow comparative analysis between different treatments. 399

11. Run samples on an HPLC using $220 \mathrm{~nm}$ as the reference wave- 400 length for detection of peptide bonds. Where multiple wave- 401 length analysis is possible, wavelengths of 254 and $280 \mathrm{~nm} 402$ should also be used for detection of disulphide bonds and aro- 403 matic residues, respectively. HPLC gradients should be as 404 detailed in Table 2. 405

12. If possible, fractionate individual peaks according to the HPLC 406 manufacturer's guidelines (Fig. 6). 407

13. Lyophilise individual peaks overnight and store at $-20^{\circ} \mathrm{C}$ until 408 tryptic digestion and characterisation by MALDI-ToF or LC/ 409 MS analysis (see Note 24). 410

Table 2

HPLC conditions $\quad$ t2.2

Time (min)

Solvent

t2. 3

\begin{tabular}{cll}
\hline $0-5$ & $5 \%$ acetonitrile & Step and hold \\
\hline $5-40$ & $5-100 \%$ acetonitrile & Gradient \\
\hline $40-42$ & $100 \%$ acetonitrile & Step and hold \\
\hline $42-44$ & $100-5 \%$ acetonitrile & Gradient \\
\hline
\end{tabular}




\section{Author's Proof}

J. Fallon et al.

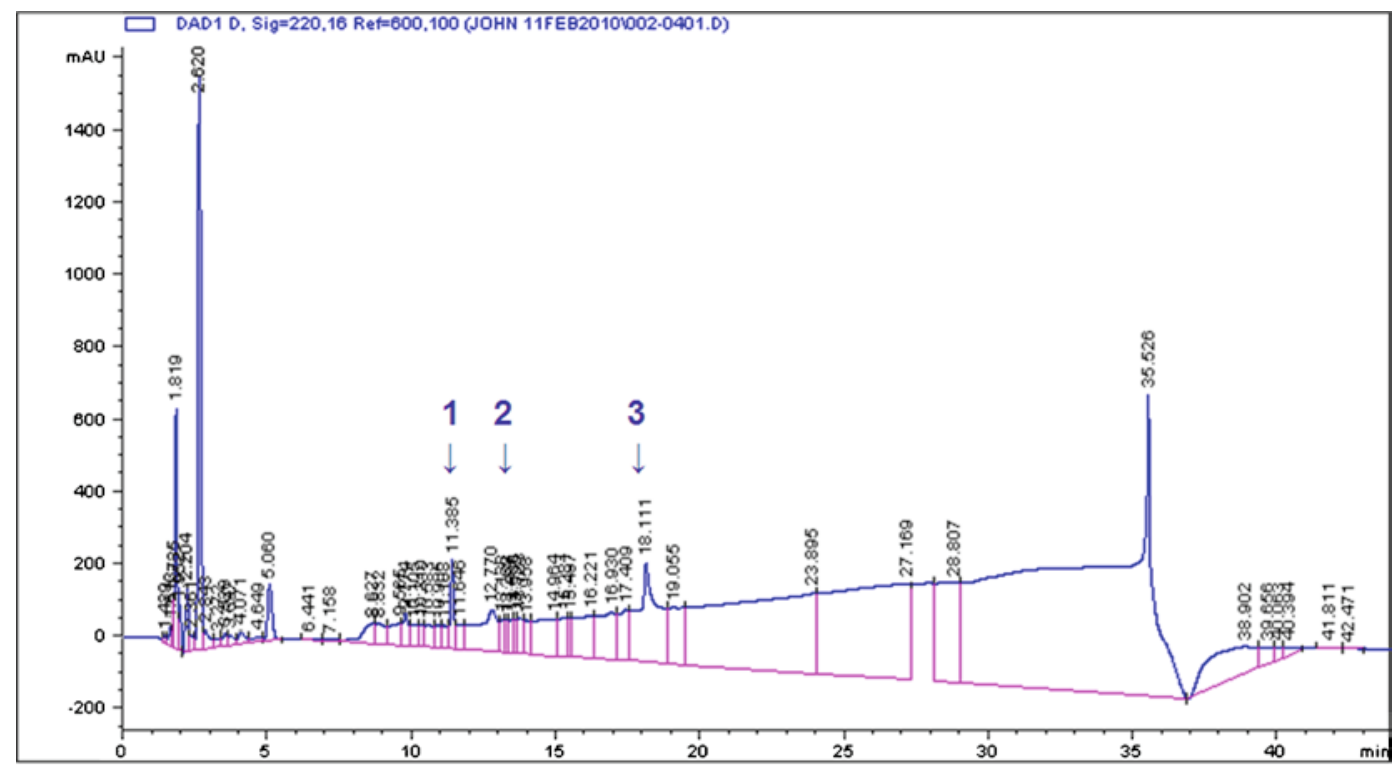

1. Larval haemolymph protein, $13.7 \mathrm{kDa}$

2. Anionic antimicrobial peptide $2,6.975 \mathrm{kDa}$

3. Apolipophorin III, $20 \mathrm{kDa}$

Fig. 6. Visualisation of G. mellonella antimicrobial peptides following HPLC fractionation.

\section{Notes}

1. G. mellonella larvae may be stored in wood shavings in the dark at $15^{\circ} \mathrm{C}$ prior to use. Larvae chosen for experiments should weigh between 0.2 and $0.4 \mathrm{~g}$ and used within $3-4$ weeks of receipt. Larvae were discarded if they appeared dark in colour due to melanisation.

2. A range of doses is used to ascertain the lethal dose for different C. albicans strains.

3. The majority of larvae are dead after $96 \mathrm{~h}$.

4. Larvae that melanise rapidly upon inoculation with a pathogen generally do not survive long, while those showing slow or little melanisation tend to survive.

5. Phenyl-3-(2-thiazolyl)-2-thiourea prevents melanisation of the haemolymph.

6. It should be possible to collect approximately $50-60 \mu \mathrm{L}$ from each larva. Ensure all white flocular material is removed; this is the fat body and will impede counting.

7. Haemocyte density varies in response to different pathogens, and ascertaining the density can give an indication of the relative virulence of a pathogen (9). 
8. Addition of erythromycin to the YEPD plates prevents bacte- 431 rial growth. 432

9. For larvae infected $24 \mathrm{~h}$ previously, we generally dilute homo- 433 genate $1 / 2,000$ in PBS prior to plating. After $24 \mathrm{~h}$ at $30^{\circ} \mathrm{C}, 434$ there are typically $10^{6}$ colonies per plate. 435

10. Virulent pathogens proliferate rapidly in the insect while weak 436 or avirulent strains either grow slowly or are eliminated by the 437 insect immune response (9). 438

11. We routinely use group sizes of 30 , with three plates each 439 containing ten larvae. $\quad 440$

12. Antimicrobial drugs can provoke an immune response in lar- 441 vae so suitable control groups must be included in order to 442 assess the actual antimicrobial activity of the test agent (15). $\quad 443$

13. To remove contaminating RNases, glassware should be baked 444 at $220^{\circ} \mathrm{C}$ for $12 \mathrm{~h}$ prior to use. Diethyl pyrocarbonate (DEPC) 445 is a strong inhibitor of RNases. It can be used at a concentra- 446 tion of $0.1 \%(\mathrm{v} / \mathrm{v})$ to treat water, which should be left stirring 447 overnight, followed by incubation at $37^{\circ} \mathrm{C}$ for a minimum of 448 $4 \mathrm{~h}$ prior to sterilisation by autoclaving. DEPC-treated water 449 should be used to prepare all buffers required for RNA extrac- 450 tion. All bottle lids, O-rings, and magnetic stirrers should be 451 soaked overnight in DEPC water and autoclaved prior use. All 452 chemicals should be weighed without the use of a spatula. 453 Gloves must be worn at all times and changed regularly. Pipette 454 tips and tubes should be taken from freshly opened bags and 455 autoclaved twice prior to use. $\quad 456$

14. Three larvae are required to obtain sufficient RNA for gene 457 expression analysis. $\quad 458$

15. Separating gels should be prepared at least $5 \mathrm{~h}$ in advance to 459 allow better polymerisation of the separating matrix. $\quad 460$

16. To pour a gel, begin by thoroughly washing the glass plates 461 with warm soapy water, rinse with $70 \%$ ethanol, and dry with 462 lint-free tissue paper to remove any residual contamination on 463 the glass. The glass plates that we routinely use are $200 \mathrm{~mm} 464$ wide and $200 \mathrm{~mm}$ long on the front and are $223 \mathrm{~mm}$ long at 465 the back, and the gels ( $12.5 \%$ acrylamide) poured are approxi- 466 mately $190 \mathrm{~mm} \times 160 \mathrm{~mm}$ and $1.5 \mathrm{~mm}$ thick. To prepare suf- 467 ficient gel solution, mix $60 \mathrm{~mL} 1.5 \mathrm{M}$ Tris- $\mathrm{HCl}, 76 \mathrm{~mL} 468$

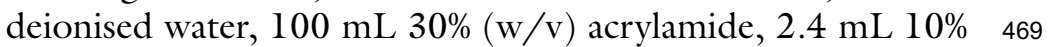
$(\mathrm{w} / \mathrm{v})$ SDS, $1.5 \mathrm{~mL} 10 \%(\mathrm{w} / \mathrm{v})$ APS, and $60 \mu \mathrm{L}$ TEMED. $\quad 470$

17. Ensure pieces are no more than 2-mm thick to allow better 471 destaining and trypsin absorption. $\quad 472$

18. This usually takes $1 \mathrm{~h}$ but may take longer depending on the 473 size of the gel piece. This process can be made faster if larger 474 pieces are sliced using a clean scalpel. 


\section{Author's Proof}

J. Fallon et al.

\section{References}

1. Kavanagh K. and Reeves E.P. (2004). Exploiting the potential of insects for in vivo pathogenicity testing of microbial pathogens. FEMS Microbiology Reviews. 28: 101-112.

2. Cotter G., Doyle S. and Kavanagh K. (2000). Development of an insect model for the in vivo pathogenicity testing of yeasts. FEMS Immunol. \& Med. Microbiol. 27: 163-169.

3. Reeves E.P., Messina C.G.M., Doyle S. and Kavanagh K. (2004). Correlation of gliotoxin production and virulence of Aspergillus fumigatus in Galleria mellonella. Mycopathologia 158: 73-79

4. Brennan M., Thomas D.Y., Whiteway M.,, and Kavanagh K. (2002). Correlation between virulence of Candida albicans mutants in mice and Galleria mellonella larvae. FEMS Immunol. \& Med. Microbiol 34: 153-157.

5. Mylonakis E., Moreno R., El Khoury J.B., Idnurm A., Heitman J., Calderwood S.B., Ausubel F.M. and Diener A. (2005). Galleria mellonella as a model system to study Cryptococcus neoformans pathogenesis. Infect. Immun. 73: 3842-3850.

6. Lionakis M.S., Lewis R.E., May G.S., Wiederhold N.P., Albert N.D., Halder G., and Kontoyiannis D.P. (2005). Toll-deficient Drosophila flies as a fast, high-throughput model for the study of antifungal drug efficacy against invasive aspergillosis and Aspergillus virulence. J Infect Dis. 191: 1188-95.

7. Fuchs B. and Mylonakis E. (2006). Using nonmammalian host to study fungal virulence and host defense. Curr. Opin Microbiol. 9: 346-351.
8. Mylonakis E. (2008). Galleria mellonella and the study of fungal pathogenesis: making the case for another genetically tractable model host. Mycopathol. 165: 1-3.

9. Bergin D., Brennan M.. and Kavanagh K. (2003). Fluctuations in haemocyte density and microbial load may be used as indicators of fungal pathogenicity in larvae of Galleria mellonella. Microb. Infect. 5: 1389-1395.

10. Bergin D., Murphy L., Keenan J., Clynes M. and Kavanagh K. (2006). Pre-exposure to yeast protects larvae of Galleria mellonella from a subsequent lethal infection by Candida albicans and is mediated by the increased expression of antimicrobial peptides. Microb. Infect. 8: 2105-2112.

11. Mowlds P., Coates C., Renwick J. and Kavanagh K. (2010). Dose-dependent cellular and humoral responses in Galleria mellonella larvae following $\beta$-glucan inoculation. Microb. Infect. 12: 146-153.

12. Tickoo S., and Russell S. (2002). Drosophila melanogaster as a model system for drug discovery and pathway screening. Curr Opin Pharmacol. 2: 555-60.

13. Hamamoto H., Kurokawa K., Kaito C., Kamura K., Manitra Razanajatovo I., Kusuhara H., Santa T., and Sekimizu K. (2004). Quantitative evaluation of the therapeutic effects of antibiotics using silkworms infected with human pathogenic microorganisms. Antimicrob. Agent. Chemother. 48: 774-779.

14. Hamamoto H., Tonioike A., Narushima K., Horie R., and Sekimizu K.(2009). Silkworm as a model animal to evaluate drug candidate 


\section{Author's Proof}

561 toxicity and metabolism. Comp. Biochem. 562

563

564

565

566

567

568

Physiol. 149: 334-339

15. Rowan R., Moran C., McCann M., and Kavanagh K. (2009). Use of Galleria mellonella larvae to evaluate the in vivo anti-fungal activity of (Ag2(mal)(phen)3). Biometals 22: 461-7.

16. Cytrnska, M., Mak, P., Zdybicka-Barabas, A., Suder, P., and Jacubowicz T. (2007).
Purification and characterization of 8 peptides 569 from Galleria mellonella immune haemolymph. 570 Peptides 28:3: 533-546.

571

17. Shevchenko, A., Tomas, H., Havlis,J., Olsen, 572 J.V., and Mann, M. (2006). In-gel digestion 573 for mass spectrometric characterization of pro- 574 teins and proteomes. Nature Protocols 1: 575 2856-2860. 